\title{
Relação das teses defendidas no Programa de Pós-Graduação Stricto Sensu em Educação da Universidade São Francisco no período de agosto de 2014 a junho de 2015
}

BERNARDO, Renata. Inserção no Ensino Superior: trajetórias de formação narradas por jovens universitários. 2015. 152p. Tese (Doutorado em Educação). Programa de Pós-Graduação Stricto Sensu em Educação. Universidade São Francisco, Itatiba, SP. Orientadora: Prof. ${ }^{a}$ Dr. ${ }^{a}$ Prof. ${ }^{a}$ Dr. ${ }^{a}$ Adair Mendes Nacarato.

A presente pesquisa ancora-se nas trajetórias de formação de jovens universitários até a inserção no ensino superior e as marcas das culturas escolares e da educação matemática escolar nestas trajetórias. A produção de dados da pesquisa foi realizada a partir de duas entrevistas narrativas e a audiogravação de dois grupos de discussão como suportes metodológicos, com o intuito de responder: Quais as marcas da matemática e da cultura escolar, jovens universitários evidenciam, ao narrarem suas trajetórias de formação até a inserção no ensino superior? A pesquisa tem como objetivo conhecer as trajetórias de formação de jovens estudantes universitários e os caminhos trilhados para inserção no ensino superior, e como objetivos específicos: 1) Conhecer as marcas das culturas escolares na trajetória de formação dos estudantes universitários; 2) Identificar as representações da matemática escolar que jovens universitários evidenciam em sua trajetória de formação; 3) Identificar os elementos determinantes na trajetória de formação para a inserção desses jovens no ensino superior. Os participantes da pesquisa são 10 estudantes universitários dos cursos de Administração, Ciências Contábeis, Enfermagem, Farmácia, Fisioterapia e Pedagogia dos Campi de Bragança Paulista e Itatiba, Estado de São Paulo, da Universidade São Francisco (USF). Os aportes teóricos do estudo alicerçam-se principalmente nos estudos sobre os jovens e os processos de inserção no sistema educacional de ensino superior evidenciando suas histórias de vida e trajetórias de formação, perpassando pelos estudos pautados nas marcas e representações da educação matemática escolar e culturas escolares. As narrativas de vida e de formação dos jovens evidenciaram que as marcas relativas às culturas escolares e à matemática escolar estão nas relações interpessoais e vínculos de amizade estabelecidos no contexto escolar; no papel do professor na trajetória de formação, sendo que os estudantes têm lembranças muito fortes de seus professores que migram de marcas positivas às negativas; na ambivalente representação da matemática escolar, em que para alguns destes jovens, de acordo com suas experiências, representa grandes dificuldades e desafios, conferindo-lhe o dom para a aprendizagem, e para outros, a matemática escolar representou prazer e facilidade em aprender. Sobre os elementos determinantes para a inserção no ensino superior, as narrativas apontam para a importância da família, o seu incentivo e apoio moral; as contingências econômicas, que interferem diretamente no processo; a influência dos professores e das disciplinas escolares; e o papel das políticas públicas para a inserção do jovem no ensino superior.

Palavras-chave: jovens universitários; trajetórias de formação; inserção no ensino superior; marcas das culturas escolares; representações da matemática escolar.

DURÇO, Marco Antônio. As táticas de professores do ensino médio frente às prescrições e os desafios do cotidiano escolar. 2015. 202p. Tese (Doutorado em Educação). Programa de Pós-Graduação Stricto Sensu em Educação. Universidade São Francisco, Itatiba, SP. Orientadora: Prof. ${ }^{a}$ Dr. $^{a}$ Prof. $^{\text {a }}$ Dr. ${ }^{a}$ Luzia Bueno.

Esta pesquisa buscou investigar como professores do Ensino Médio da cidade de Araxá (interior do estado de Minas Gerais) desenvolvem e utilizam táticas para poderem sobreviver em seus cotidianos escolares. A pesquisa foi realizada com a colaboração de um professor e uma professora de matemática da rede pública estadual do município de Araxá, MG ambos com mais de 20 anos de magistério, professores para os quais foram dados "voz e ouvidos" para saber o que dizem sobre as suas condições de trabalho docente, suas rotinas de trabalho, sobre seu cotidiano escolar e perceber quais são as táticas que estes professores desenvolvem e utilizam em seu cotidiano escolar que lhes permitiam sobreviver frente aos questionamentos, adversidades e prescrições que lhes são imputadas. A intenção foi o acompanhamento dos caminhos de suas atividades docentes, mapeando e analisando as entrevistas realizadas sobre suas rotinas de trabalho, tanto dentro de sala de aula como nas atividades inerentes aos professores: reuniões, semana de prova, correção de exercícios, dentre outras. Assim, apresenta-se como hipótese desta tese se os professores entrevistados desenvolvem e utilizam táticas de sobrevivência face às atividades prescritas e realizadas. Desta forma, objetivou-se na pesquisa: (1) Investigar as táticas de professores do ensino médio da rede pública estadual de Minas Gerais frente às prescrições e/ou 
regulações e desafios do cotidiano escolar; (2) Investigar como as táticas são produzidas e utilizadas nas prescrições e regulações do trabalho docente, desses professores, desenvolvidos no interior e fora da sala de aula. Pôde-se apresentar, neste trabalho, uma análise das táticas que estão presentes na constituição da profissionalidade docente, das táticas que surgem diante das atuais condições de trabalho docente no interior da sala de aula, as táticas que permitem dar um (re) significado às regulações e às prescrições do trabalho docente no estado de Minas Gerais e as táticas para utilização do Portal Virtual do Professor, apresentado pela Secretaria de Estado de Educação de Minas Gerais. Tais táticas, em nenhum momento, se contrapuseram às estratégias apresentadas pelas prescrições e regulações, apenas apresentaram uma maneira de "burlar" as regras apresentadas, sem, contudo, trazer prejuízo para os alunos. Assim, esta pesquisa se apresenta como forma de contribuição para a área de investigação sobre o trabalho docente de professores da rede pública no estado de Minas Gerais, podendo servir como um banco de dados para governos e pesquisadores da área educacional no desenvolvimento de novos e eficientes projetos educacionais.

Palavras-chave: táticas do professor, condições do trabalho docente, educação matemática, ensino médio.

GARÉ, Ruth Maria Rodrigues. Educação formal x educação não formal: diferentes práticas de ensino e a construção de identidades surda. 2014. 219p. Tese (Doutorado em Educação). Programa de Pós-Graduação Stricto Sensu em Educação. Universidade São Francisco, Itatiba, SP. Orientadora: Prof. ${ }^{a}$ Dr. ${ }^{a}$ Márcia Aparecida Amador Mascia.

Considerando-se as lacunas pedagógicas para o ensino-aprendizagem, na educação formal do surdo, de modo especial, na educação pública, este trabalho procurou lançar um olhar problematizador às questões de ensino tentando levantar as práticas de letramento ao surdo em dois contextos de educação: formal e não formal. Outro aspecto em destaque é a discussão sobre as representações de mães e de alunos, na tentativa de compreender estes alunos e as diferentes identidades produzidas nestes espaços. A pesquisa tomou como aporte teórico autores que trabalham na perspectiva foucaultiana, além do próprio Foucault e a Análise do Discurso de Linha Francesa. O corpus de análise foi composto por entrevistas filmadas e posteriormente transcritas com ajuda dos recursos do Sistema de Transcrição de Língua de Sinais (Quadros), da Análise da Conversação e das contribuições da Análise do Discurso, como subsídio para interpretação dos dados coletados. Os sujeitos da pesquisa são surdos em contexto de educação formal em sala de aula regular e sem intérprete e visitados por um grupo religioso em contexto não formal. Surdo em escola regular com apoio no contraturno, surdo fora da escola regular e também assistido pelo grupo e, finalmente as mães dos surdos e suas expectativas em relação aos seus filhos. Em Portugal, em especial, na cidade de Braga, buscou-se conhecer para descrever os diferentes contextos de educação dos surdos, a fim de compor um capítulo a parte, com objetivo de acirrar ainda mais as discussões em torno das práticas de letramento dos surdos e as identidades construídas. A presente pesquisa traz resultados perturbadores que apontam para a construção de identidades ouvintes e/ou incompletas, ao procurar respostas às perguntas como: que tipos de sujeitos surdos e identidades emergem em dois contextos de ensino-aprendizagem (em dois tipos de educação formal e em um não formal)? Quais as contribuições de um contexto não formal para os contextos formais, no que tange às práticas pedagógicas para surdos? Qual a concepção de currículo que permeia as três práticas? Desta forma, com a descrição das identidades dos sujeitos da pesquisa e que emanam nos contextos formal e não formal, com suas diferentes práticas de ensino, buscou-se levantar a partir dessas estratégias de ensino e suas implicações na formação do sujeito surdo, novas formas de pensar a educação do surdo no nosso país. A pesquisa pretende contribuir para a compreensão do impacto dessas diferentes identidades construídas nestes diferentes contextos, em relação ao uso, difusão e manutenção da Língua de Sinais e consequentemente a comunidade surda. Esta tese pretende chamar a atenção para a necessidade de ações políticas no sentido de dar ao surdo uma educação que comporte um currículo que comporte as dimensões do mesmo currículo ouvinte, porém com todas as adaptações necessárias, a fim de garantir as mesmas oportunidades da comunidade oral.

Palavras-Chave: Surdo; Discurso; Identidade Surda; Educação Formal e Educação Não Formal.

LIMA, Josciene de Jesus. Governamentalidade e modos de identificação: tramas discursivas de/sobre professores da educação básica. 2015. 190p. Tese (Doutorado em Educação). Programa de Pós-Graduação Stricto Sensu em Educação. Universidade São Francisco, Itatiba, SP. Orientadora: Prof. ${ }^{a}$ Dr. ${ }^{a}$ Márcia Aparecida 
Amador Mascia.

Esta pesquisa investigou professores(as) de uma escola pública na Bahia, tendo como instrumento de levantamento do corpus, entrevistas semi-estruturadas, aplicadas junto a seis professores da Educação Básica, sendo quatro professores(as) e duas gestoras. Considerando-se que existem outros sentidos e que sempre há possibilidades de estranhamento ao olhar o que supostamente se pensa conhecer, resolvemos lançar um novo olhar à escola "locus" da pesquisa, com a qual mantenho laços. Também motivou o tema e a escolha do local da pesquisa, o fato de observarmos a inexistência de trabalhos científicos que tematizem os(as) professores(as) e as escolas da cidade/município mencionada, considerando um momento em que se discute a desvalorização social e econômica, atrelada à identidade do professor da escola básica. Baseada em pressupostos da linha francesa da Análise do Discurso e nos estudos foucaultianos, a partir das relações de poder-saber e na governamentalidade como formadora de subjetividades, tomou-se por hipótese que os dizeres dos(as) professores(as) e acerca dos(as) professores(as) transitam entre o mesmo e o diferente, fazendo emergir os conflitos e as lutas que atravessam os sujeitos-professores(as) no processo de constituição dos seus modos de identificação, como sujeitos divididos que convivem com o amor e o ódio, com o dever e o prazer, mas que também resistem resistindo na profissão, hipótese essa confirmada a partir das entrevistas e análise dos dados. Os objetivos que nortearam a pesquisa são: Identificar os efeitos de sentido que apontam para os modos de identificação dos(as) professores(as), nas falas de: professores(as), gestores e coordenadora pedagógica; Apontar os regimes de verdade e as relações de podersaber que permeiam as políticas educacionais e apontam para as formas de governamentalidade do(a) professor(a), a partir da interdiscursividade dos sujeitos de pesquisa; Identificar, nas falas dos(as) professores(as), as formas de resistência e sua relação com os modos de identificação; Mostrar como os modos de identificação dos(as) professores(as) se materializam linguisticamente. Optou-se por trabalhar na vertente de „modos de identificação dos(as) professores(as) ${ }^{\text {ee }}$ por considerarmos que o contexto sócio-histórico e a ideologia possibilitam a constituição das subjetivações e a ideologia sob diferentes modos. Assim, os(as) professores(as) se identificam com a profissão docente de diferentes modos, por aspectos positivos e por aspectos negativos, pelo dito, pelo não dito e pelo dito de outra forma, de acordo com os estudos de Michel Pêcheux e Eni Orlandi. As formações discursivas dos sujeitos mostraram identificação pelo amor e pelo desamor, revelando marcas de conflitos externos e internos, presença de sujeitos heterogêneos, revelando-se divididos entre o ser ou não ser professor e entre o sair ou permanecer na profissão docente. Entretanto, como marca de resistência, os(as) professores(as) resistem resistindo à profissão e se firmando na função de professor(a). Emergem sujeitosprofessor com uma imagem positiva de si, como profissional, mas com baixa auto-estima em relação à profissão docente. Espera-se que esta pesquisa contribua no sentido de se refletir sobre a imagem do(a) professor(a) e como esta pode influenciar nos modos de identificação, podendo nortear novas pesquisas e provocar inquietações e tomada de decisão por parte dos produtores diretos das políticas públicas.

Palavras-chave: Modos de identificação dos professores. Governamentalidade. Profissão docente. Análise do Discurso.

MACHADO, Raquel Fernandes Gonçalves. Trilhando caminhos pelas culturas, relações temporais e espaciais em aulas de matemática em uma turma de EJA. 2015. 217p. Tese (Doutorado em Educação). Programa de Pós-Graduação Stricto Sensu em Educação. Universidade São Francisco, Itatiba, SP. Orientadora: Prof. ${ }^{a}$ Dr. ${ }^{a}$ Adair Mendes Nacarato.

Nessa pesquisa, investigamos as relações culturais, espaciais e temporais evidenciadas em ações propostas junto a um grupo de alunos de uma turma de $9^{\circ}$ ano do ensino fundamental da Educação de Jovens e Adultos (EJA), do colégio de aplicação de uma instituição de ensino público federal, no interior de MG. Objetivou-se compreender como se articulam as diferentes culturas no contexto dessa turma, reportando-nos às culturas: da Educação de Jovens e Adultos, da sala de aula e da aula de matemática na EJA, bem como compreender como são as relações espaciais e temporais produzidas no processo de ensino e de aprendizagem, da referida disciplina. Esta é uma pesquisa de abordagem qualitativa, na qual os instrumentos de produção de dados utilizados para a documentação consistiram em: áudio e vídeogravações de aulas de matemática e dos momentos em que os alunos resolveram tarefas sobre geometria; do diário de campo da pesquisadora, do questionário sobre o perfil, da produção oral e escrita destes alunos. O processo de análise focou nos seguintes eixos de análise que emergiram dos dados: (1) o entrecruzamento de culturas: a cultura na/da EJA, a cultura da sala de aula (de 
Matemática) e a cultura na/da aula na EJA; (2) as relações temporais e espaciais nocontexto de EJA. Os teóricos nos quais nos fundamentamos foram Freire (2010, 2011, 2012, 2013, 1994), Fonseca (2001,2002, 2005), Hiebert et. al (1997), referendando-nos para a compreensão do entrecruzamento de culturas evidenciadas; Escolano (2001) e Viñao Frago (2001), para nossas referências espaciais e temporais; Arroyo (2007), para as relações temporais. Os resultados indicaram o quanto os alunos participantes desta pesquisa se envolveram com as tarefas propostas, se permitiram ser desafiados, conseguiram dizer a sua palavra, destacando-se como sujeitos de seu aprendizado. Nossas análises dos dados produzidos na trajetória desta pesquisa evidenciam o quanto as relações espaço-temporais, perpassadas pelos silêncios foram significativas no processo de ensino e aprendizagem destes alunos. E, ainda, o quanto contribuíram para o processo de formação da pesquisadora. As análises evidenciam ainda a importância de uma reorganização das propostas curriculares, re-significando o tempo destes alunos ao explorarem conteúdos de geometria.

Palavras-chave: Educação de Jovens e Adultos. Cultura de aula de Matemática, Geometria.

PERBONI, Edilene Mizael de Carvalho. Os sujeitos das políticas de avaliação sistêmica da alfabetização em Minas Gerais: uma analítica à luz da governamentalidade. 2015. 188p.Tese (Doutorado em Educação). Programa de Pós-Graduação Stricto Sensu em Educação. Universidade São Francisco, Itatiba, SP. Orientadora: Prof. ${ }^{a}$ Dr. ${ }^{a}$ Ana Paula de Freitas. Coorientadora: Profa. Dra. Jackeline Rodrigues Mendes.

Tudo começa com um sujeito pesquisador, que ao assistir o vídeo - Vida Maria, num encontro da SEE/MG, faz alguns questionamentos sobre o Programa de avaliação da alfabetização em Minas Gerais - PROALFA. Esses questionamentos despertam para o problema de pesquisa: Quais sujeitos e perspectivas curriculares emergem da análise das políticas de avaliação sistêmica da qualidade da alfabetização em Minas Gerais? Para a análise das políticas de avaliação, nos dois primeiros capítulos, são tomados alguns elementos da Análise de Discurso Crítica - ADC, com foco na concepção tridimensional do Discurso: Prática social, Prática discursiva e Texto. O capítulo I, à luz da ferramenta analítica da Governamentalidade, aponta para como as políticas de avaliação estão imbricadas em redes de poder produzidas no cenário econômico e político do sistema educacional internacional, nacional e estadual. O capítulo II traz a análise de dois documentos: a Resolução SEE/MG n ${ }^{\circ}$ 1086/2008 e alguns excertos da Matriz de Referência de Teste do SIMAVE/PROALFA. No capítulo III, há um distanciamento da ADC, uma vez que são discutidos os sujeitos avaliados na avaliação sistêmica mineira, na perspectiva de — constituição do sujeitoll em Larrosa, - tecnologias de si e -cuidado de si em Foucault. Nas discussões teóricas do capítulo III, são trazidos dois filmes: -Shrek 1 e -Vida Mariall. Quanto aos sujeitos que emergem dessas políticas de avaliação, fazemos dois destaques: primeiro refere-se ao sujeito preconizado nos resultados, que é regulado por regras — anônimas\| de quem — pode enunciar e o que — pode ser enunciado, de acordo com os padrões de desempenho; o segundo trata-se do sujeito que tem como possibilidade, frente ao próprio processo avaliativo e seus resultados, o — cuidar de si, como - prática de liberdade.

Palavras-chave: Avaliação Sistêmica (SIMAVE/PROALFA), Sujeito e Governamentalidade.

PIRES, Natal Junio. O governamento dos cientistas em tempos neoliberais: reflexões acerca da performatividade e da competição no meio acadêmico brasileiro no período de 1968 a 2014. 2015. Tese (Doutorado em Educação). Programa de Pós-Graduação Stricto Sensu em Educação. Universidade São Francisco, Itatiba, SP. Orientadora: Prof. ${ }^{a}$ Dr. ${ }^{a}$ Alexandrina Monteiro.

Este trabalho de pesquisa tem como foco problematizar algumas práticas decorrentes do modo como se dá, na atualidade, o financiamento e os incentivos às pesquisas em ciência, assim como ocorre a formação de alunos no meio acadêmico brasileiro. Para isso, me utilizo de algumas das teorizações desenvolvidas pelo filósofo francês Michel Foucault - e também das reflexões de intelectuais afinados com o trabalho desse pensador - , tomando como ferramenta o conceito governamentalidade, mais especificamente aquele que permeia os ideais neoliberais. Ainda neste sentido, faço uso dos conceitos de capital humano, conforme trazidos por Gary Becker e Theodore Schultz, e o conceito de performatividade na perspectiva em que o utiliza Stephen Ball. Em minha análise, parto de documentos publicados pela UNESCO, bem como de planos/programas de estímulo à ciência, tecnologia e inovação e leis - instituídos pelo governo — que visam garantir o desenvolvimento científico e tecnológico. Faz parte da análise também os dados estatísticos acerca dos resultados oriundos desse processo de culto à 
ciência como ferramental econômico para resolver problemas sociais. E, por fim, exploro uma série de documentos publicados nos últimos anos na área da Química, os quais acredito darem importantes pistas de como essas políticas influem na fabricação de subjetividades por parte dos cientistas, bem como podem apontar para uma série de consequências - não necessariamente boas, e em boa medida creio não serem boas - , que emergem no cotidiano acadêmico atual. A partir destes documentos, levanto algumas questões acerca das práticas por eles incitadas. Assinalo que tais documentos, dentre seus objetivos, visam, num primeiro momento, a incorporação por parte dos atores do meio acadêmico — discentes, docentes, dirigentes, etc.- - de imperativos tais como, desenvolvimento, investimento em capital humano, produtividade, performatividade, competição, educação científica e tecnológica com vistas à transformação do social, assim como crescimento econômico e aumento da força de competição. Posteriormente, examino, digamos como que, num segundo momento, como esses imperativos passam a ressonar no meio acadêmico e a fazer parte do imaginário dos cientistas, os quais são cooptados de forma pouco ou até nada resistível, e às vezes de forma até prazerosa pela força dessas ideias. A aceitação de tudo isso só faz contribuir para o fortalecimento do neoliberalismo, e como apontarei adiante, não sem consequências. Portanto, neste trabalho, procuro contribuir com uma reflexão acerca dos prováveis efeitos que tais práticas, baseadas na lógica do neoliberalismo, podem trazer para a produção de subjetividades nos sujeitos que circulam pelo meio acadêmico, assim como colocar sob suspeita a pretensa visão salvacionista da ciência como meio para extinguir os problemas sociais.

Palavras-chave: Governamentalidade; Performatividade; Capital Humano; Ciência e Tecnologia.

RIFFEL, Birgit Yara Frey. Enxergando no escuro: saberes e práticas sociais de sujeitos com deficiência visual. 2015. 256p. Tese (Doutorado em Educação). Programa de Pós-Graduação Stricto Sensu em Educação. Universidade São Francisco, Itatiba, SP. Orientadora: Prof. ${ }^{a}$ Dr. ${ }^{a}$ Jackeline Rodrigues Mendes.

A inclusão de pessoas com deficiência na escola regular vem se consolidando no Brasil contemporâneo, trazendo consigo mudanças significativas no cotidiano escolar. O objetivo desta tese é problematizar - especificamente no campo de jovens com cegueira - esta inclusão, interrogando as formas como tem ocorrido, com quais objetivos e conexões, tentando compreender as diferentes subjetividades a que este grupo social é submetido. Isto não significa, entretanto, se opor à inclusão, mas situá-la dentro de um contexto de relações de poder e produções discursivas, de forma que nos permita perceber seus efeitos sobre a constituição dos sujeitos. Os conceitos de governamentalidade e normalização de Foucault foram utilizados como ferramentas analíticas, inspirando a correlação entre as políticas públicas destinadas a regulamentar, ordenar e consolidar direitos das pessoas com deficiência e as práticas pedagógicas das instituições educacionais. A abordagem metodológica foi de cunho etnográfico, apoiada em referenciais teóricos pós-críticos. Para subsidiar a discussão foram acompanhados durante dezoito meses três jovens cegos congênitos estudantes do ensino fundamental, na escola regular, na especializada e em práticas sociais diversas, como esporte, lazer e dança. Além deles, outros dois sujeitos adultos, com a mesma deficiência sensorial, um estudante universitário e professor de escola especializada e outro coordenador desta mesma escola, colaboraram com suas experiências e vivências para enriquecer a pesquisa. Todos vivem em uma cidade de médio porte localizada no oeste de Minas Gerais, na região do Alto do Paranaíba. As entrevistas destes sujeitos, aliadas aos registros de campo e análise de textos legais, formam o corpo desta tese, entrelaçados a quadros teóricos e históricos relativos ao tema. A análise foi conduzida com foco em quatro eixos principais, fisicamente pouco delimitados e que portanto se cruzam durante toda a discussão: a normalização dos sujeitos com deficiência, a exclusão na inclusão, a sociabilização integradora e a estigmatização do outro. A interpretação destes elementos leva a considerar que a lógica econômica vigente em nosso país tem influência preponderante na produção das políticas públicas atuais, conduzindo os sujeitos a uma condição de autorregulação, normalização e competição. Em relação aos aspectos educacionais, foi possível perceber que o reconhecimento e apropriação de saberes diversos daqueles predominantes ainda não se consolidaram em nosso sistema escolar. Preceitos pedagógicos e curriculares permanecem visuocentrados, dificultando a inclusão efetiva de alunos com deficiência visual na escola regular. Sob este aspecto a Etnomatemática é discutida, posto que concebe a matemática como conceito plural, sendo desafiada a fazer emergir e circular as variadas estratégias que existem e são apropriadas por diferentes sujeitos em suas práticas de mobilização cultural.

Palavras-chave: Deficiência visual. Inclusão. Normalização. Visuocentralidade. 
SPIANDORELLO, Simone Cristina. Relações sociais na educação: padre Saboia e a escola superior de administração de negócios - ESAN. 2015. 208p. Tese (Doutorado em Educação). Programa de Pós-Graduação Stricto Sensu em Educação. Universidade São Francisco, Itatiba, SP. Orientadora: Prof. ${ }^{a}$ Dr. ${ }^{a}$ Maria de Fátima Guimarães.

O desenvolvimento industrial e o grande crescimento populacional da cidade de São Paulo nas primeiras décadas do século passado, impulsionados, principalmente, pela imigração estrangeira, são parte do contexto de grandes transformações como a translação do poder econômico para a emergente classe industrial, da articulação de movimentos trabalhistas e de consolidação dos ideais republicanos, dentre eles o Ensino Superior, pensado para formar uma elite intelectual capaz de realizar a pretendida modernização do país. Foi nesse contexto que se deu a criação da primeira escola de administração em nível superior no país, a Escola de Administração de Negócios ESAN, fundada, em 1941, em São Paulo, pelo padre jesuíta Roberto Saboia de Medeiros cuja trajetória foi muito marcada por sua atuação junto aos grupos de formação de trabalhadores e por suas contribuições à contenção dos movimentos anarquistas e do comunismo. Os fragmentos da história de constituição da ESAN narradas nesta pesquisa foram reconstituídos a partir das cartas escritas por Roberto Saboia de Medeiros a seu pai, e demonstram de que forma as redes de relações sociais, por ele constituídas, deram suporte às suas realizações, tendo na Campanha do Continho sua mais forte representação. O Continho foi um esquema de recebimento de donativos de pessoas físicas e jurídicas, que financiou a criação da ESAN, bem como, de outras obras ligadas a Ação Social, entidade jurídica criada por Saboia para abrigar e gerenciar, além da ESAN, obras de assistência social, uma gráfica e a Faculdade de Engenharia Industrial - FEI. A reconstituição dessa parte da história da ESAN a consolida como a primeira escola de administração em nível superior a ser criada no Brasil e trás contribuições para a história do ensino de administração no país.

Palavras-chave: Ensino de Administração; Escola Superior de Administração de Negócios, Padre Saboia, Administração Científica, Relações Sociais na Educação.

TRAVA, Sandra Memari. O trabalho docente de uma professora: práticas de leitura em foco. 2015. 180p. Tese (Doutorado em Educação). Programa de Pós-Graduação Stricto Sensu em Educação. Universidade São Francisco, Itatiba, SP. Orientadora: Prof. ${ }^{a}$ Dr. ${ }^{a}$ Luzia Bueno.

Essa pesquisa tem por objetivo refletir sobre o trabalho docente com a leitura, especificamente, o trabalho de uma professora do Ciclo I, do Ensino Fundamental, que

leciona nas séries iniciais da Rede Pública de São José dos Campos. Procuramos depreender os aspectos tematizados sobre o trabalho com a leitura nos textos de uma entrevista semiestruturada e de uma entrevista de autoconfrontação simples. Para isso, evidenciamos os pressupostos teórico-metodológico do Interacionismo Sociodiscursivo, que apresenta a linguagem como papel fundamental no/para o desenvolvimento humano, tendo como fontes de referências os estudos de Bronckart (2003, 2006, 2009); Machado (2004); Bueno (2007, 2011), juntamente aos aportes teóricos da Ergonomia da Atividade (AMIGUES, 2004; SAUJAT, 2004) e aos aportes teóricos da Clinica da Atividade (CLOT, 2010; FAÏTA, 2002). A coleta de dados foi realizada em uma escola pública da Rede Estadual de Ensino paulista, tendo como sujeito de pesquisa uma professora alfabetizadora voluntária. Os dados foram coletados por meio de entrevistas semiestruturada, videogravação das aulas e posteriormente a realização da entrevista de autoconfrontação simples. As análises foram constituídas por recortes do texto das entrevistas semiestruturada e autoconfrontação simples, nas quais procuramos observar o contexto de produção e os aspectos tematizados pela professora em relação ao trabalho com a leitura. Os resultados nos permitem enfatizar a complexidade do trabalho docente com a leitura e a necessidade que o professor tem em responder as várias demandas que lhe são impostas como: ministrar todo o conteúdo proposto, seguir o livro didático, o planejamento, os projetos oferecidos pelos órgãos como: Secretaria da Educação, Oficinas pedagógicas, etc. Esperamos que as reflexões realizadas possam contribuir para a compreensão do trabalho docente, principalmente com práticas de leitura e para a percepção da importância de se observar o trabalho concreto do professor tanto em sala de aula como fora do horário escolar.

Palavras-chave: Autoconfrontação simples; Interacionismo Sociodiscursivo; Trabalho. 